mental knowledge and to technological progress. Much of the Association's technological work in this field has contributed to the drafting of British Standard specifications and similarly, at the international level, to the recommendations of such bodies as the International Electrotechnical Commission. During the past year the Electrical Research Association's recommendations relating to electrode systems for electric strength tests and for methods of measurement of permittivity and loss angle have been so adopted.

Work conducted at the National Physical Laboratory on the effects of electron and neutron irradiation of polythene is reported. It has been shown that the loss tangent of the material is little affected by irradiation dosages up to $10 \mathrm{Mrads}$, but thereafter increases due to oxidation.

Among the investigations of a fundamental character concerning the phenomena of instability in dielectrics, one may be mentioned dealing with the formation of gas in impregnated insulation. This has established the relation between moisture content and the stress required to initiate gas production. It has been possible to observe the slow growth of breakdown channels in a very viscous liquid and this forms the subject of one of the illustrations in the report.

A reliable technique has been developed for measuring the electric strength of liquefied gases, it having been established that the state of the electrode surfaces and particularly the degree of oxidation have a marked influence on the result. The parts played by anode and cathode have been separated by using electrodes in which the cathode and anode surface were different.

The influence of impurities on the magnetic properties of silicon-iron transformer sheet has been under investigation at the laboratories of the British Iron and Steel Research Association. It has been shown that, with respect to hysteresis loss, nitrogen is much more harmful than carbon, and two methods of minimizing the ill-effects of nitrogen are being examined. One method involves applying a thin coating of aluminium to laminations before annealing while the other utilizes a small admixture of titanium.

Theoretical work on deviations from Ohm's law in semiconductors has predicted that in sufficiently strong fields mobility should decrease with the $0 \cdot 8$ th power of the field strength. This prediction has been confirmed by measurements made at Purdue University.
Circuit breaking and associated fundamental studies in arc physies continue to constitute an important part of the research programme. The temperature within the conducting core of the arc and, in particular, the formation of successive discrete cores as the current increases, have been studied in terms of dissociation and ionization, and it has been shown that the pinch pressures occurring at the electrodes outweigh the effects of natural convection and may provide an explanation of the phenomena of metal transfer in welding arcs.

Work on the creep properties of steel continues and is being extended. The first test-results have been obtained on the bursting of thick-walled pipes under creep conditions. A new laboratory to meet the needs of the augmented programme of work on creep testing is to be built at Leatherhead.

A result of considerable industrial significance has been obtained in the course of the programme of work on flame proofness and intrinsic safety. A reevaluation of the maximum safe-gap for hydrogen made with improved research technique has shown the safe gap to be appreciably greater than was previously accepted. The value has been established as 11 mils. This opens up the possibility of designing flame-proof apparatus for use in hydrogen and some of the other most explosive gases.

The rural electrification work of the Association, which is concerned very largely with the application of electricity to agriculture and to horticulture, has, in the past, embodied a considerable programme of research on plant environment. This continues but it is now supplemented by a parallel programme on animal environment.

In a foreword to the report the president, Sir Josiah Eccles, points out that we are entering an era in which the scale and complexity of equipment and of automatic control systems will be such as to render capital charges a dominant factor in industrial costs.

There will thus be an increasing premium on ingenuity and skill in producing more effective and cheaper equipment which, in effect, means an increasing emphasis on research. Bearing in mind that the vast majority of manufacturing firms in Great. Britain employ less than 500 people and that many problems can be better tackled co-operatively than in specialized laboratories, it is evident that research associations have an important part to play in the effort to develop to the full the nation's scientific potential. In furthering this development the greatest responsibility falls, almost certainly, to the electrical industry.
J. Greig

\title{
FLOW PROPERTIES OF BIOLOGICAL SYSTEMS
}

\begin{abstract}
A
MEETING, under the joint auspices of the Faraday Society (Colloid and Biophysics Committee) and the British Society of Rheology, was held during September 23 and 24 in the School of Physiology of the University of Oxford. On the first day, the flow properties of various biological systems were discussed, while the second day was devoted entirely to blood and blood vessels. The attendance of more than seventy included a number of overseas guests.

The Conference was opened by Prof. P. R. Allison. Nuffield professor of surgery, who welcomed the
\end{abstract}

meeting to Oxford and spoke of the increasing importance of rheology in medicine and surgery. A general introductory lecture, under the chairmanship of Prof. M. Reiner (Haifa, Israel), was given by Dr. A. S. Lodge. Many of his audience were not rheologists and, for their benefit, Dr. Lodge outlined the scope and methodology of this branch of physics.

Several papers were read which concerned uterine cervical mucus and the connective tissue of the cervix. Dr. F. K. Beller (Tübingen, W. Germany) described 
the rheological changes which take place in human mucus during the menstrual cycle and following certain hormone treatments, and Dr. R. A. Gibbons and Mr. F. A. Glover (National Institute for Research in Dairying, Shinfield) discussed measurements of flow birefringence and the information which these might give concerning the size and shape of mucoid molecules. Drs. M. L. R. and D. R. Harkness (University College, London) were concerned with the very marked changes which must take place in the lower end of the uterus and in the cervix to allow of the passage of the fotus at parturition. The concentration of collagen drops from 10 per cent (wet basis) in the non-pregnant animal to about a third of this amount during pregnaney.

Drs. J. C. White and P. Elmes (London Postgraduate Medical School) described viscosity, intrinsic vis cosity and thixotropy measurements on dilute bronchial mucoid sputum. A special apparatus was designed to measure the yield-values of undiluted samples, which may be related to the force required to initiate movement of the mucus in the smaller respiratory passages. Dr. H. J. Rogers discussed hyaluronidase and hyaluronic acid.

Living skeletal muscle has remarkable rheological properties, contracting rapidly and completely from extensions of up to 130 per cent, but this extreme elasticity is quickly lost post mortem. J. R. Bendall (Low Temperature Research Station, Cambridge) spoke of the form of the deformation-time curves and the biochemical processes underlying the changes which take place in them. Also concerned with muscle, Dr. J. J. Connell (Torry Research Station, Aberdeen) described measurements of toughness and firmness of fish and of fish pastes and jellies as related to subjective assessments.

Prof. L. V. Heilbrunn (Philadelphia) discussed methods for measuring the rheological properties of protoplasm, and stressed the differences between these and the behaviour of purified proteins. Prof. J. A. V. Butler and Dr. A. B. Robins (Chester Beatty Research Institute, London) described simple viscometric measurements (using concentric cylinders) for the study of nucleic acid solutions; and the significance of intrinsic viscosities and of viscous anomalies such as dependence of viscosity on shear rate.

Dr. G. W. Scott Blair (National Institute for Research in Dairying, Shinfield) read two papers, the first of which dealt with the rather complex properties of milk coagulated by rennet which, at best, requires four parameters for its specification ('Burgers body'). On the second day, he described similar experiments on coagulated blood, which, surprisingly enough, except in the earliest stages, requires only two parameters ('Maxwell body').

The symposium on blood was introduced by Dr. L. W. Bayliss (University College, London) under the chairmanship of Prof. I. de Burgh Daly. Dr. Bayliss outlined studies which have been made on viscous anomalies in blood flowing through artificial capillaries, emphasizing the importance of the relatively easier flow which is found in the narrower tubes and which reflects axial movement of corpuscles. Dr. R. L. Whitmore (Nottingham) gave a theoretical treatment of these differential flow velocities of plasma and corpuscles in the living body. By means of radioactive tracers, changes in concentration due to radial movements can be followed. He discussed turbulent conditions, which also formed the theme of a paper by Dr. W. E. Stehbens (Sydney, Australia and Oxford), who pointed out that, espec- ially in the neighbourhood of bifurcations, turbulence takes place at quite low Reynolds' numbers. Nor must the pulsatile nature of the flow be forgotten. Stream. line conditions are not as general in the body as used to be supposed. Dr. D. A. MeDonald also discussed the hydrodynamies of pulsatile flow, basing his treatment on the theoretical work of the late Dr. J. R. Womersley and of Dx. M. G. Taylor.

Prof. A. L. Copley (New York and London) diseussed the nature of the flow-curve of blood in glass eapillaries which has recently been shown to follow Casson's equation (see G. W. Scott Blair, Nature, 183, 613; 1959). When the surface of the capillary is coated with fibrin, the apparent viscosity falls and the differential flow velocities appear to be accentuated. Moving 'indexes' of blood in sloping capillaries also adhere less to fibrin than to glass surfaces. In the living blood vessel, an endo-endothelial fibrin film may constitute a major factor in helping circulation. He also presented work on native blood and plasma and the effects of anticoagulants.

Prof. S. Baez (New York) described pressure effects in living microscopic vessels and pointed out the important part which the tone of the vasculature plays, not only in hæmodynamics but also in those studies now often referred to as 'hæmorheology'. Dr. H. Hartert (Heidelberg, Western Germany) discussed the rheology of his well-known technique for following the process of blood coagulation by measuring the progressive increase in shear modulus ("thromboelastography') and also described his more recent invention, the 'retractograph', which follows the process of retraction, claimed to start immediately at the clotting point and to increase in parallel with increase in the shear modulus. Dr. H. H. Pfeiffer (Bremen, Western Germany) described his measurements of rheodichroism, a phenomenon which throws much light on the molecular nature and characteristics of the so-called 'leptones' which are responsible for differential light absorption in flow. Prof. A. Katchalsky (Rehovoth, Israel) and his colleagues discussed recent experiments on osmotic effects in individual erythrocytes. These behave rather like football bladders, in that they are very readily deformed up to a certain degree of swelling, after which they offer enough resistance for the pressure quickly to exceed their apparent strength, a fact which may help to account for the comparative ease with which red cells appear to pass along very narrow vessels.

In the afternoon of the second day of the meeting, there was an exhibition of apparatus. Many of the instruments associated with the papers which had been read were on view. The demonstrations were introduced by a lecture by Prof. K. Weissenberg in which he showed many strange rbeological phenomena which, in less dramatic form, are likely to make their appearance in biological systems. His own 'rheogoniometer' was among the exhibits.

In the evening, films were shown which developed further the themes already described by Dr. D. L. MeDonald and his colleagues, by Prof. S. Baez and by Prof. A. L. Copley, Dr. G. W. Scott Blair and their colleagues. Finally, Prof. M. H. Knisely (Charleston) showed a film to illustrate his work on 'sludged blood'.

Much of the success of the meeting was due to the excellent local organization, in the hands of Dr. R. G. Macfarlane, who also acted as honorary treasurer. The proceedings of the Conference will be published in book form early in the New Year under the joint editorship of Prof. A. L. Copley and Dr. G. Stainsby. G. W. ScotT BLaIR 